\title{
Filamentation protects Candida albicans from amphotericin B-induced programmed cell death via a mechanism involving the yeast metacaspase, MCA1
}

\author{
David J. Laprade, Melissa S. Brown\#, Morgan L. McCarthy\#, James J. Ritch, and Nicanor Austriaco* \\ Department of Biology, Providence College, 1 Cunningham Square, Providence, Rhode Island 02918, U.S.A.. \\ " These two authors contributed equally to this work. \\ * Corresponding Author: \\ Rev. Nicanor Pier Giorgio Austriaco, O.P., Ph.D, Department of Biology, Providence College, Providence, RI 02918, U.S.A; Tel: +1 401- \\ 865-1823; Fax: +1 401-865-2959; E-mail: naustria@providence.edu
}

\begin{abstract}
The budding yeast Candida albicans is one of the most significant fungal pathogens worldwide. It proliferates in two distinct cell types: blastopores and filaments. Only cells that are able to transform from one cell type into the other are virulent in mouse disease models. Programmed cell death is a controlled form of cell suicide that occurs when $C$. albicans cells are exposed to fungicidal drugs like amphotericin $B$ and caspofungin, and to other stressful conditions. We now provide evidence that suggests that programmed cell death is cell-type specific in yeast: Filamentous $C$. albicans cells are more resistant to amphotericin B- and caspofungin-induced programmed cell death than their blastospore counterparts. Finally, our genetic data suggests that this phenomenon is mediated by a protective mechanism involving the yeast metacaspase, MCA1.
\end{abstract}

doi: 10.15698/mic2016.07.512

Received originally: 06.05.2015;

in revised form: 25.01.2016,

Accepted 18.03.2016,

Published 25.04.2016.

Keywords: Candida albicans, amphotericin B, caspofungin, MCA1, programmed cell death, filamentation.
Abbreviations:
$A M B$ - amphotericin $B$,
CAS - caspofungin,
FBS - fetal bovine serum,
GIcNAc-N-acetylglucosamine,
ROS - reactive oxygen species.

\section{INTRODUCTION}

The budding yeast Candida albicans has emerged as one of the most significant fungal pathogens globally [1]. As an opportunistic pathogen capable of life-threatening systemic infections, $C$. albicans poses a serious threat to immunocompromised individuals, including AIDS patients, cancer patients undergoing chemotherapy, organ transplant recipients, and patients with advanced diabetes [2-4]. Worldwide, invasive candidiasis is currently regarded as the fourth most common cause of nosocomial infections with an estimated mortality rate of $35 \%[5,6]$. Significantly, resistance to therapies traditionally used to treat candidiasis such as triazoles and amphotericin $B$ is rising $[7,8]$. Thus, there is a pressing need to develop more effective anti-fungal treatments.

There are a number of physiological characteristics of C. albicans known to contribute to its virulence. Most notably, the organism's ability to undergo a reversible mor- phological transition from round, budding cells called 'blastospores,' to elongated cells attached end-to-end, called 'filaments,' is linked to its ability to infect a host: cells unable to become filamentous or vice versa have been shown to be avirulent in mouse and $C$. elegans models [9-18]. The process by which $C$. albicans undergoes the transition from blastospores to filaments is known as 'filamentation'. Within the filamentous form, we further individuate two distinct cellular morphologies. Pseudo-hyphal cells are attached end-to-end, exhibit constrictions at the septa, and have an elongated cell wall, while true hyphal cells of $C$. albicans are distinguished by the emergence of small cellular protrusions called 'germ tubes'. While a recent study has shown that virulence can be decoupled from cell type in C. albicans, the connection between cell type and pathogenicity remains an important one [19].

Interestingly, there is growing evidence to support the claim that the drugs commonly used to treat patients suf- 

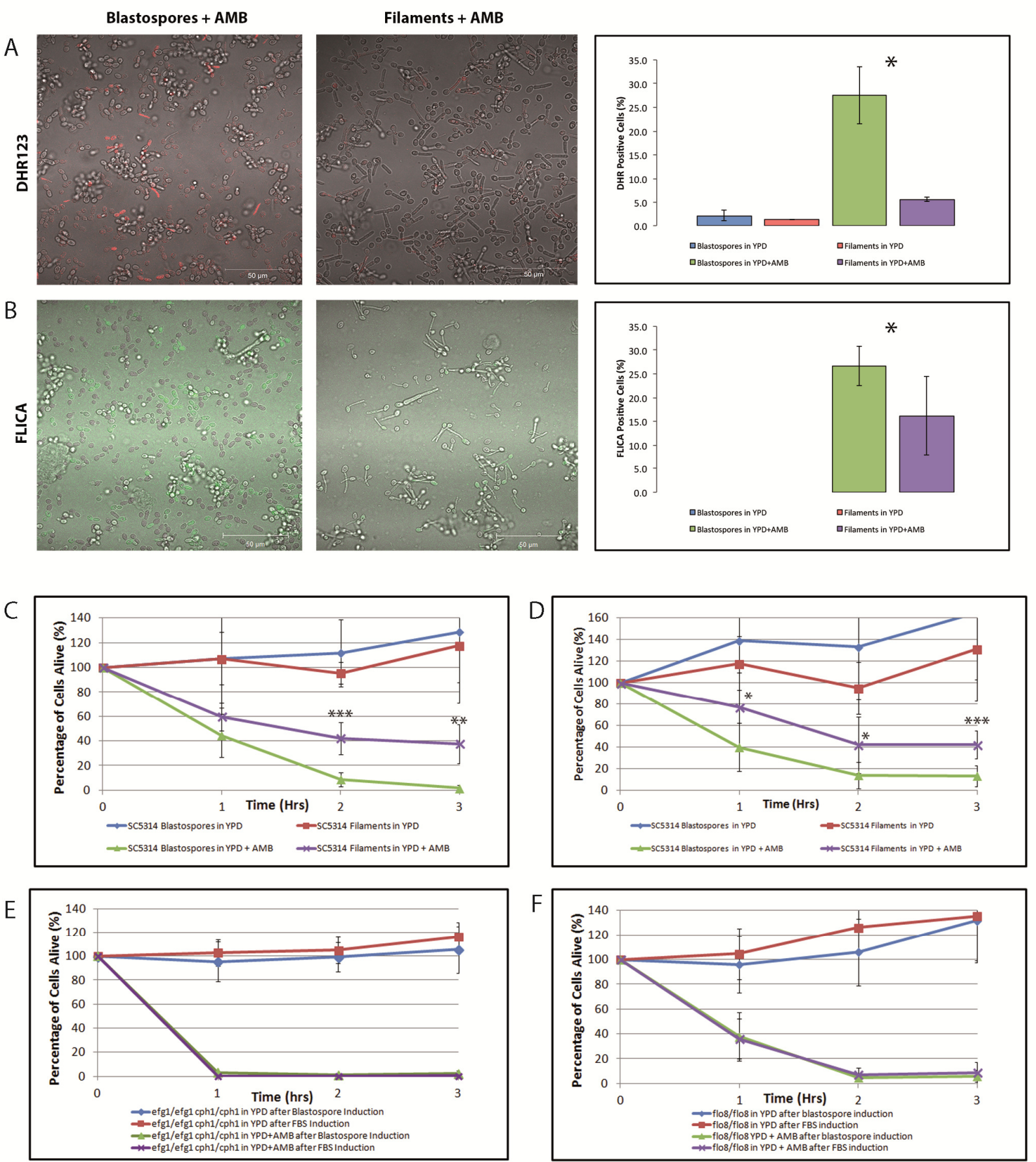

FIGURE 1: Filamentous $C$. albicans cells are more resistant than blastospores to AMB-induced programmed cell death. Exposure to amphotericin B leads to the generation of reactive oxygen species (ROS) and to caspase activation in C. albicans cells. Representative confocal scanning laser fluorescence images of wild-type SC5314 C. albicans cells treated with $8 \mu \mathrm{g} / \mathrm{ml} \mathrm{AMB}$ for 3 hours in YPD. Staining with dihydrorhodamine 123 (DHR123) confirms the presence of ROS (A) and with the FLICA assay for activation of intracellular caspases (B). Error bars indicate standard deviations for trials with at least three independent cultures, where at least 300 cells were counted for each trial. No FLICA positive cells were observed in the no drug controls. A single asterisk indicates statistical significance $(p<0.05)$ as compared to treated controls. Statistical significance was determined with the unpaired Student's t-test. Scale bar: $50 \mu \mathrm{m}$. Viability curves compare survival of the following cells exposed to AMB: (C) wild type blastospores and wild type filaments induced using $10 \%$ FBS; (D) wild type blastospores and wild type filaments induced using $0.5 \mathrm{~g} / \mathrm{l} \mathrm{GlcNAc}$; (E) $\Delta \Delta$ efg1/efg $1 \mathrm{cph} 1 / \mathrm{cph} 1 \mathrm{cells}$ in YPD and $\Delta \Delta$ efg1/efg1 $\mathrm{cph} 1 / \mathrm{cph} 1$ cells following filamentous induction in YPD $+10 \% \mathrm{FBS}$, and (F) $\Delta \Delta$ flo8/flo 8 cells in YPD and $\Delta \Delta$ flo8/flo 8 cells following filamentous induction in YPD $+10 \%$ FBS. Note that after $3 \mathrm{hr}$, cells cultured in rich media without any drugs were able to grow and to divide, hence the relative viability levels that are greater than $100 \%$. Error bars indicate standard deviations for trials with at least three independent cultures. A single, double, and triple asterisk indicates a significance of $p<0.05, p<0.005$, and $p<0.0005$, respectively, as compared to treated controls. Statistical significance was determined with the unpaired Student's t-test. 
fering from C. albicans infections, induce cell death [20, 21]. Specifically, $C$. albicans cells cultured in media containing the common anti-fungal drugs, amphotericin $B$ (AMB) and caspofungin (CAS), undergo an apoptotic-like programmed cell death [22-25]. Programmed cell death is a cell suicide program that is essential for homeostasis, development, and disease prevention in many multi-cellular organisms [26-29]. When it occurs in yeast, programmed cell death is accompanied by the nicking of DNA, the accumulation of reactive oxygen species (ROS), and the intracellular activation of the fungal caspases [30-37].

In multicellular organisms, the response to programmed cell death is cell-type specific, and the rate of cell death varies widely from tissue to tissue and cell-type to cell-type within the plant or animal [26]. In this paper, we provide evidence that suggests that programmed cell death is also cell-type specific in yeast: filamentous Candida cells are more resistant to amphotericin B- and caspofungin-induced programmed cell death than their blastospore counterparts. Finally, our genetic data suggests that this phenomenon is mediated by a mechanism involving the yeast metacaspase MCA1.

\section{RESULTS AND DISCUSSION}

In recent years, it has become evident that programmed cell death occurs in unicellular organisms. For example, in the pathogenic fungus Candida albicans exposure to acetic acid, hydrogen peroxide, AMB, CAS, and farnesol leads to cell death accompanied by hallmark features of mammalian programmed cell death [22-24, 36, 38]. In multicellular organisms, the response to programmed cell death is celltype specific, and the rate of cell death varies widely from tissue to tissue and cell type to cell type within the plant or animal [26]. To determine whether or not different forms of yeast respond differently to stimuli that induce programmed cell death, we first investigated whether or not filamentous cells manifest the markers of programmed cell death when they are cultured in media containing AMB. In this study, the clinical isolate SC5314-the parent of strains widely used for molecular analysis-was used as the wild type strain [39]. Briefly, overnight cultures of wild type cells in YPD were resuspended in YPD or YPD containing $10 \%$ fetal bovine serum (YPD+FBS) to obtain either blastospores or hyphal cells respectively (Supplemental Figure 1) [10-12]. These cells were then resuspended in YPD containing $8 \mu \mathrm{g} / \mathrm{ml}$ AMB for 3 hours. Dihydrorhodamine 123 and FLICA staining confirmed that both these AMB-treated blastospores and filamentous cells accumulated ROS and activated caspases, respectively-two classic markers of programmed cell death - and were undergoing cell death as revealed by staining with propidium iodide (Figure 1). With both markers, however, there were fewer markerpositive filamentous cells as compared to blastospore controls, suggesting that the former cell type was more resistant to AMB.

Next, we compared the viability of wild-type Candida albicans cells in the blastospore and filamentous forms when cultured in media containing $8 \mu \mathrm{g} / \mathrm{ml} \mathrm{AMB}$ with control cultures grown in YPD alone. Clonogenic survival assays are routinely used to assay programmed cell death in yeast $[10,23,24,40,41]$. As shown in Figure 1C, hyphal cells had a higher viability when cultured in media containing AMB than their blastospore counterparts $(p<0.005)$. This data suggests that filamentation protects Candida cells from $A M B$-induced programmed cell death and that this type of programmed cell death is cell-type specific in yeast.

However, because hyphae were induced by culturing blastospores in media containing FBS [11], it is possible that the differences in clonogenic survival rate could be attributed to culture conditions-namely, the presence of FBS-rather than to filamentation. To rule out this alternative explanation for our observations, we repeated our assays with a filamentation induction protocol that used $\mathrm{N}$ acetylglucosamine (GICNAC) instead of $\operatorname{FBS}[42,43]$. As shown in Figure 1D, GlcNAc-induced filamentous cells were also more resistant than their blastospore counterparts to AMB-induced cell death. Still, it could be argued that the difference in survival rate observed between the two cell types was only due to the variable presence of either FBS or GICNAc. To respond to this concern, we repeated our experiments with Can36, a SC5314-derived mutant yeast strain lacking $C P H 1$ and EFG1, two putative transcription factors necessary for filamentation in Candida [12]. As expected, this strain was unable to undergo filamentation in media containing 10\% FBS (Supplemental Figure 1). However, as shown in Figure $1 \mathrm{E}$, the viability of the $\Delta \Delta c p h 1 / c p h 1$ efg1/efg1 mutant yeast cells cultured in FBS and exposed to $A M B$ was indistinguishable from that of mutant yeast cells cultured in media with $A M B$ alone. Finally, we repeated our assay a fourth time with CCF3, a SC5314-derived $\Delta \Delta$ flo8/flo8 strain that is also unable to undergo filamentation when cultured in FBS [10]. Again, this non-filamentous mutant was unable to survive when cultured in the presence of $A M B$ regardless of whether or not it was first cultured in the presence of FBS [Figure 1F]. Complementation of the $\Delta \Delta$ flo8/flo8 strain confirmed that this phenotype, along with the inability to undergo filamentation, are both dependent upon the null $\Delta \Delta$ flo8/flo 8 mutation as others had previously shown [10]. Thus, we conclude that the resistance pattern noted in both nonfilamentous mutants is not related to secondary effects of the mutations distinct from their inability to undergo filamentation, and that FBS itself is unable to protect yeast cells from AMB-induced programmed cell death. Together, these experiments suggest that filamentation protects yeast cells against AMB-induced programmed cell death.

To investigate the mechanism behind this anti-cell death phenomenon, we decided to focus on the yeast metacaspase, MCA1, a homolog of the mammalian caspases linked to apoptosis in metazoans. The MCA1 homolog in S. cerevisae, YCA1, has been implicated in programmed cell death: mutants lacking YCA1 in S. cerevisae exhibit lower levels of intracellular caspase activation and significantly decreased levels of programmed cell death when 

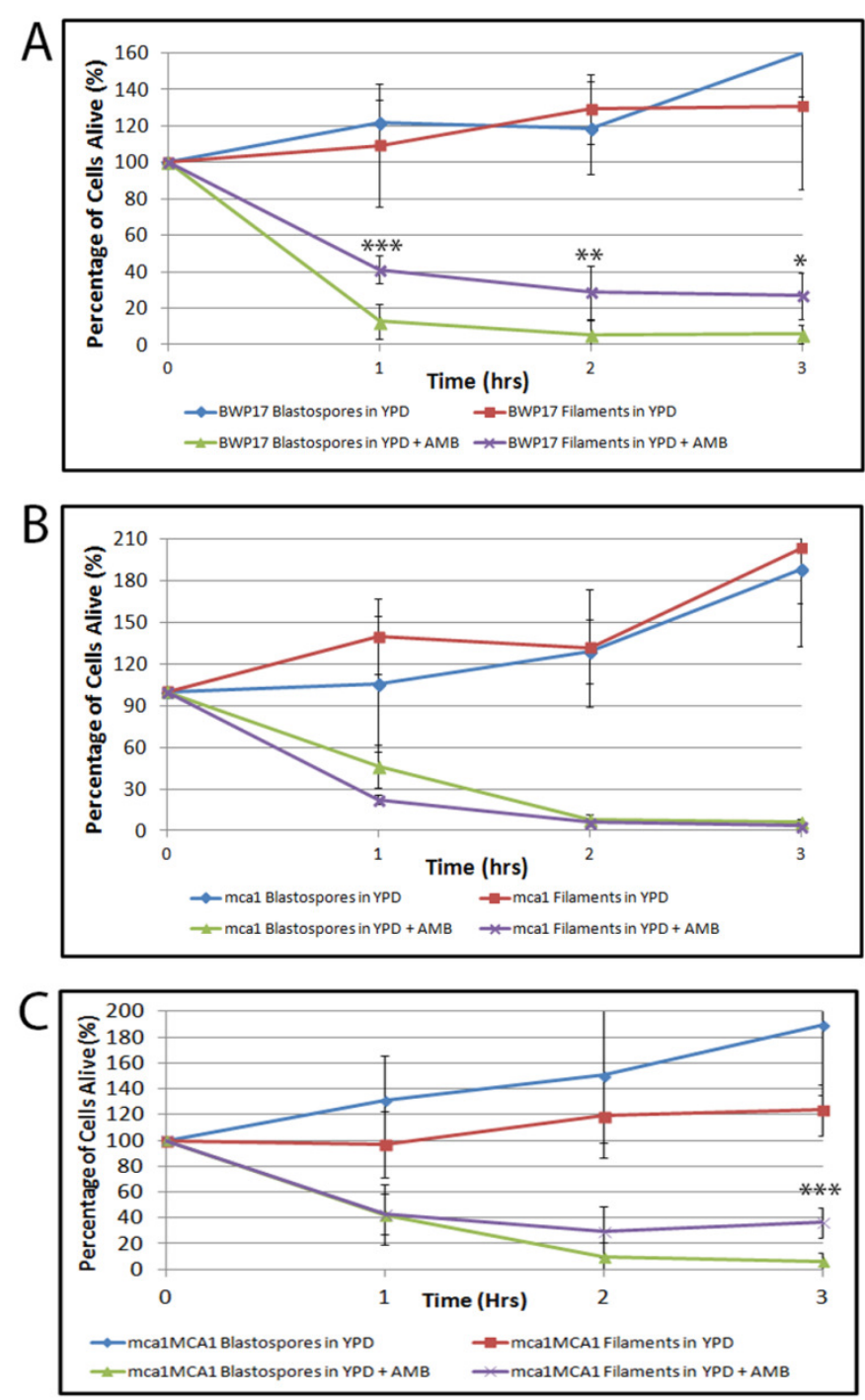

exposed to hyposomatic stress $[32,44]$. We compared the survival rate of the wildtype BWP17 blastospores and filaments with their BWP17-derived $\Delta \Delta$ mca1/mca1 mutant counterparts. Wildtype and all mca1 mutants were able to undergo filamentation when exposed to $10 \%$ FBS (Supplemental Figure 2). As shown in Figure 2, $\Delta \Delta$ mca1/mca1 blastospores and hyphal cells had indistinguishable survival rates when cultured in media containing AMB. This data suggests that MCA1 is involved in the resistance of filamentous cells to $A M B$-induced programmed cell death. Complementation of the null $\Delta \Delta$ mca1/mca1 mutant restored the original difference in viability that we had observed between blastospore and hyphal cells cultured in AMBcontaining media, suggesting that the original $\Delta \Delta m$ ca1/mca1 phenotype could be linked to the original lossof-function mutation in MCA1. In sum, our data suggests that filamentation protects $C$. albicans cells from AMB induced cell death and that this phenotype is dependent upon the yeast metacaspase, MCA1. Given that MCA1 has previously been thought to have a pro-death function, it is not yet clear how Mca1p functions in this protective capacity in filamentous cells. However, it is intriguing that sever-
FIGURE 2: Filamentous $C$. albicans cells are more resistant than blastospores to AMB-induced programmed cell death in an MCA1-dependent manner. Viability curves compare survival of the following cells exposed to AMB: (A) wild type (BWP17) blastospores and BWP17 filaments induced using $10 \%$ FBS; (B) BWP17-derived $\Delta \Delta$ mca1/mca1 blastospores and $\Delta \Delta \mathrm{mca} 1 / \mathrm{mca} 1$ filaments induced using $10 \% \mathrm{FBS}$; and (C) $\Delta \Delta m$ ca1/mca1::MCA1 blastospores and $\triangle \triangle$ mca1/mca1::MCA1 filaments induced using 10\% FBS. Error bars indicate standard deviations for trials with at least three independent cultures. Note that after $3 \mathrm{hr}$, cells cultured in rich media without any drugs were able to grow and to divide, hence the relative viability levels that are greater than $100 \%$. A single, double, and triple asterisk indicates statistical significance of $p<0.05, p<$ 0.005 , and $p<0.0005$, respectively, as compared to treated controls. Statistical significance was determined with the unpaired Student's t-test. al recent papers have revealed that the Mca1p homolog has a non-death role in S. cerevisae and possibly, in C. albicans as well [36, 45-49].

Finally, we wanted to determine if filamentation protected Candida cells from another anti-fungal drug known to induce programmed cell death. Thus, we compared the viability of blastospores and hyphal cells in media containing $0.05 \mu \mathrm{g} / \mathrm{ml}$ caspofungin (CAS), an echinocandin known to trigger cell death, in Candida albicans $[22,23]$. As shown in Figure 3, filamentation also appears to protect yeast cells from CAS-induced cell death suggesting the protective effects of filamentation may be a general phenomenon in Candida albicans. Watamoto et al. have proposed that filamentous Candida cells are resistant to AMB and to nystatin because they are able to form biofilms $[17,50]$. In light of our findings, we also propose that planktonic hyphal cells may in themselves be relatively more resilient to these drugs - and possibly other anti-fungal drugs as wellbecause of their heightened resistance to programmed cell death. 

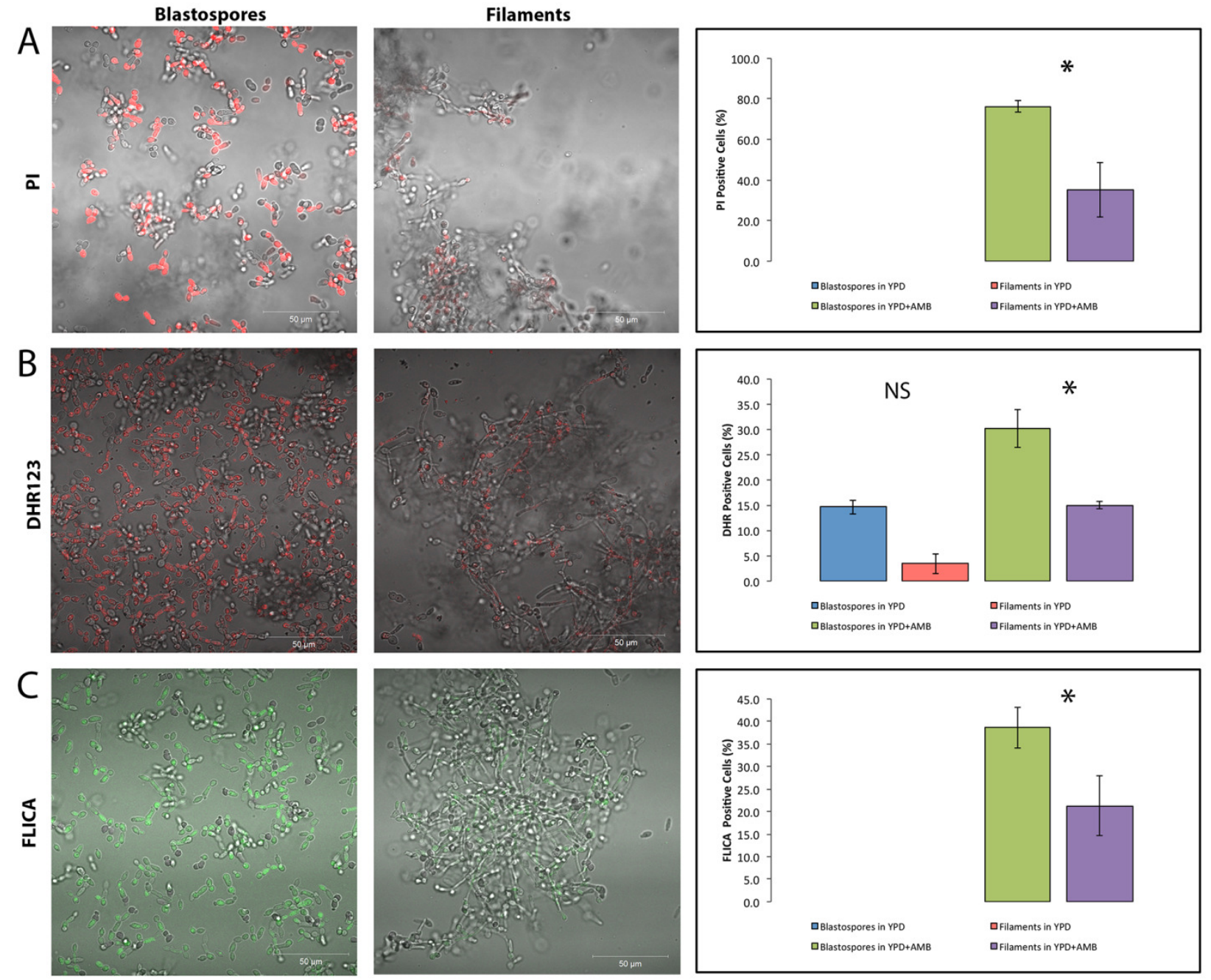

FIGURE 3: Filamentous $C$. albicans cells are more resistant than blastospores to caspofungin-induced programmed cell death. Representative confocal scanning laser fluorescence images of wild-type SC5314 C. albicans cells treated with $0.05 \mu \mathrm{g} / \mathrm{ml}$ caspofungin for 3 hours in YPD. Propidium iodide stains dead cells, dihydrorhodamine 123 (DHR123) indicates the presence of reactive oxygen species (ROS), and the FLICA assay stains for cells with activated intracellular caspases. No PI or FLICA positive cells were observed in the no drug controls. Error bars indicate standard deviations for trials with at least three independent cultures, where at least 300 cells were counted for each trial. A single asterisk indicates statistical significance $(p<0.05)$ as compared to treated controls. Statistical significance was determined with the unpaired Student's t-test.

\section{MATERIALS AND METHODS}

\section{Media and Growth Conditions}

C. albicans cells were grown in yeast extract/peptone/dextrose broth (YPD) made according to standard recipes [51]. Cells were inoculated from single colonies growing on YPD plates into $20 \mathrm{ml}$ YPD and grown under shaking at $30^{\circ} \mathrm{C}$ until the culture attained an $\mathrm{OD}_{600}$ value of $2.00 \mathrm{~A}$. Once the culture had reached $\mathrm{OD}_{600} \approx 2.0 \mathrm{~A}$, cells were harvested and then resuspended in fresh media at a concentration of $3 \times 10^{7}$ cells $/ \mathrm{ml}\left(\mathrm{OD}_{600} \approx 1.26 \mathrm{~A}\right)$. For blastospore induction, cells from the original culture were resuspended in fresh YPD, transferred to a sterile flask, and then grown under shaking at $30^{\circ} \mathrm{C}$ for 3 hours. For hyphal induction, harvested cells were resuspended in either YPD $+10 \%$ fetal bovine serum (HyClone) pre-warmed to $37^{\circ} \mathrm{C}$ (YPD + FBS) or YPD + N-acetylglucosamine at a concentration of $0.5 \mathrm{~g} / \mathrm{l}$ GlcNAc (Sigma-Aldrich;
YPD+GIcNAc), transferred into a fresh flask, and placed in an incubator with shaking at $37^{\circ} \mathrm{C}$ for 3 hours $[11,12,42,43,52]$.

\section{Viability Assays}

Blastospores and hyphal cells were harvested and resuspended at a concentration of $1 \times 10^{7}$ cells $/ \mathrm{ml}$ in fresh YPD, and placed in $15 \mathrm{ml}$ conical tubes. Cells were then exposed to AMB (Sigma) at a concentration of $5 \mu \mathrm{g} / \mathrm{ml}$ or $8 \mu \mathrm{g} / \mathrm{ml}$ (from a 1 $\mathrm{mg} / \mathrm{ml}$ stock in dimethyl sulfoxide) for 3 hours, with shaking, at $25^{\circ} \mathrm{C}$ [24]. At $\mathrm{t}=0,1,2$, and 3 hours of $\mathrm{AMB}$ exposure, serial dilutions of the cell cultures were done on YPD plates. The plates were then placed in a $30^{\circ} \mathrm{C}$ incubator for 24 to 48 hours, or until single colonies were distinguishable. Colonies for each time point were counted and then compared as a percentage of the number of colonies that formed on the $t=0$ plate. For each time point, three independent cultures were tested. 
Notably, we confirmed our clonogenic assays by directly visualizing dead filamentous cells using propidum iodide (50 $\mu \mathrm{g} / \mathrm{ml}$ ) and then counting them with a Zeiss LSM700 fluorescent microscope. For the experiments with caspofungin, blastospores and filaments were cultured in the drug at a concentration of $0.05 \mu \mathrm{g} / \mathrm{ml}$ (from a $1 \mathrm{mg} / \mathrm{ml}$ stock in dimethyl sulfoxide) for 3 hours, with shaking, at $25^{\circ} \mathrm{C}$. The viability of the cells was determined by culturing them in propidium iodide (50 $\mu \mathrm{g} / \mathrm{ml}$ ) and then counting them visually with a Zeiss LSM700 fluorescent microscope. Again, three independent cultures were tested, and at least 300 cells were counted for each determination. Statistical significance for all experiments was determined with the unpaired Student's t-test.

\section{In Vivo Detection of ROS Accumulation and Caspase Activa- tion}

Intracellular ROS accumulation was examined after treatment with $\mathrm{AMB}$ or caspofungin using $5 \mathrm{\mu g} / \mathrm{ml}$ of dihydrorhodamine 123 (DH123; Sigma Aldrich) [24]. Activated caspases were detected in C. albicans cells after treatment with AMB or CAS using a FLICA apoptosis detection kit (ImmunoChemistry Technologies, LLC) according to the manufacturer's specifications [38]. After exposure to either DHR123 or the FLICA reagent, $C$. albicans cells were harvested and examined using a Zeiss 700 Confocal Laser Scanning Microscope.

\section{SUPPLEMENTAL MATERIAL}

All supplemental data for this article are available online at www.microbialcell.com.

\section{REFERENCES}

1. Guinea J (2014). Global trends in the distribution of Candida species causing candidemia. Clinical microbiology and infection : the official publication of the European Society of Clinical Microbiology and Infectious Diseases 20 Suppl 6:5-10.

2. Cassone A, Cauda R (2012). Candida and candidiasis in HIVinfected patients: where commensalism, opportunistic behavior and frank pathogenicity lose their borders. AIDS (London, England) 26(12): 1457-72.

3. Grossi PA (2009). Clinical aspects of invasive candidiasis in solid organ transplant recipients. Drugs 69 Suppl 1:15-20.

4. Sensoy G, Belet N (2011). Invasive Candida infections in solid organ transplant recipient children. Expert review of anti-infective therapy $9(3)$ : 317-24.

5. Pfaller M, Neofytos D, Diekema D, Azie N, Meier-Kriesche HU, Quan SP, Horn D (2012). Epidemiology and outcomes of candidemia in 3648 patients: data from the Prospective Antifungal Therapy (PATH Alliance(R)) registry, 2004-2008. Diagnostic microbiology and infectious disease 74(4): 323-31.

6. Mikulska M, Del Bono V, Ratto S, Viscoli C (2012). Occurrence, presentation and treatment of candidemia. Expert review of clinical immunology 8(8): 755-65.

7. Huang M, Kao KC (2012). Population dynamics and the evolution of antifungal drug resistance in Candida albicans. FEMS microbiology letters 333(2): 85-93.

8. Pfaller MA (2012). Antifungal drug resistance: mechanisms, epidemiology, and consequences for treatment. The American journal of medicine 125 (1 Suppl): S3-13.

\section{ACKNOWLEDGMENTS}

We thank Valmik K. Vyas and Gerald Fink (Massachusetts Institute of Technology), Haoping Liu (University of California, Irvine), and Renata Santos (Institut Jacques Monod) for strains, and Richard Bennett (Brown University) for technical advice. Our laboratory is supported by the following grants awarded to N. Austriaco: NIGMS R15 GM094712, NIGMS R15 GM110578, NSF MRI-R2 0959354, and NIH Grant 8 P20 GM103430-14 to the Rhode Island INBRE Program.

\section{CONFLICT OF INTEREST}

The authors declare no conflict of interest.

\section{COPYRIGHT}

(C) 2016 Laprade et al. This is an open-access article released under the terms of the Creative Commons Attribution (CC BY) license, which allows the unrestricted use, distribution, and reproduction in any medium, provided the original author and source are acknowledged.

Please cite this article as: David J. Laprade, Melissa S. Brown, Morgan L. McCarthy, James J. Ritch, and Nicanor Austriaco (2016). Filamentation protects Candida albicans from amphotericin Binduced programmed cell death via a mechanism involving the yeast metacaspase, MCA1. Microbial Cell 3(7): 285-292. doi: 10.15698/mic2016.07.512

9. Brennan M, Thomas DY, Whiteway M, Kavanagh $K$ (2002). Correlation between virulence of Candida albicans mutants in mice and Galleria mellonella larvae. FEMS immunology and medical microbiology 34(2): 153-7.

10. Cao F, Lane S, Raniga PP, Lu Y, Zhou Z, Ramon K, Chen J, Liu H (2006). The Flo8 transcription factor is essential for hyphal development and virulence in Candida albicans. Molecular biology of the cell 17(1): 295-307.

11. Kadosh D, Johnson AD (2005). Induction of the Candida albicans filamentous growth program by relief of transcriptional repression: a genome-wide analysis. Molecular biology of the cell 16(6): 2903-12.

12. Lo HJ, Kohler JR, DiDomenico B, Loebenberg D, Cacciapuoti A, Fink GR (1997). Nonfilamentous $C$. albicans mutants are avirulent. Cell 90(5): 939-49.

13. Pukkila-Worley R, Peleg AY, Tampakakis E, Mylonakis E (2009). Candida albicans hyphal formation and virulence assessed using a Caenorhabditis elegans infection model. Eukaryotic cell 8(11): 1750-8.

14. Staib $P$, Binder A, Kretschmar M, Nichterlein T, Schroppel K, Morschhauser J (2004). Tec1p-independent activation of a hyphaassociated Candida albicans virulence gene during infection. Infection and immunity $72(4)$ : 2386-9.

15. Fuchs BB, Eby J, Nobile CJ, El Khoury JB, Mitchell AP, Mylonakis E (2010). Role of filamentation in Galleria mellonella killing by Candida albicans. Microbes and infection / Institut Pasteur 12(6): 488-96.

16. Laforet L, Moreno I, Sanchez-Fresneda R, Martinez-Esparza M, Martinez JP, Arguelles JC, de Groot PW, Valentin-Gomez E (2011). Pga26 mediates filamentation and biofilm formation and is required for virulence in Candida albicans. FEMS yeast research 11(5): 389-97. 
17. Watamoto $T$, Samaranayake LP, Egusa H, Yatani H, Samaranayke YH, Seneviratne CJ (2010). Susceptibility of Candida albicans filamentation-defective mutants to clinical biocides. The Journal of hospital infection 74(2): 189-91

18. O'Meara TR, Veri AO, Ketela T, Jiang B, Roemer T, Cowen LE (2015). Global analysis of fungal morphology exposes mechanisms of host cell escape. Nature communications 6:6741.

19. Noble SM, French S, Kohn LA, Chen V, Johnson AD (2010). Systematic screens of a Candida albicans homozygous deletion library decouple morphogenetic switching and pathogenicity. Nature genetics 42(7): 590-8.

20. Ramsdale $M$ (2008). Programmed cell death in pathogenic fungi. Biochimica et biophysica acta 1783(7): 1369-80.

21. Almeida B, Silva A, Mesquita A, Sampaio-Marques B, Rodrigues F, Ludovico $P$ (2008). Drug-induced apoptosis in yeast. Biochimica et biophysica acta 1783(7): 1436-48.

22. Chin C, Donaghey F, Helming K, McCarthy M, Rogers S, Austriaco $N$ (2014). Deletion of AIF1 but not of YCA1/MCA1 protects Saccharomyces cerevisiae and Candida albicans cells from caspofungin-induced programmed cell death. Microbial Cell 1(2): 5863.

23. Hao B, Cheng S, Clancy CJ, Nguyen MH (2013). Caspofungin kills Candida albicans by causing both cellular apoptosis and necrosis. Antimicrobial agents and chemotherapy 57(1): 326-32.

24. Phillips AJ, Sudbery I, Ramsdale M (2003). Apoptosis induced by environmental stresses and amphotericin B in Candida albicans. Proceedings of the National Academy of Sciences of the United States of America 100(24): 14327-32.

25. Lin SJ, Austriaco N (2014). Aging and cell death in the other yeasts, Schizosaccharomyces pombe and Candida albicans. FEMS Yeast Res 14(1): 119-35

26. Kerr JF, Wyllie AH, Currie AR (1972). Apoptosis: a basic biological phenomenon with wide-ranging implications in tissue kinetics. British journal of cancer 26(4): 239-57.

27. Ameisen JC (2002). On the origin, evolution, and nature of programmed cell death: a timeline of four billion years. Cell death and differentiation 9(4): 367-93.

28. Zmasek CM, Godzik A (2013). Evolution of the animal apoptosis network. Cold Spring Harbor perspectives in biology 5(3): a008649.

29. Teng X, Hardwick JM (2015). Cell death in genome evolution. Seminars in cell \& developmental biology 39:3-11.

30. Carmona-Gutierrez D, Eisenberg T, Buttner S, Meisinger C, Kroemer G, Madeo F (2010). Apoptosis in yeast: triggers, pathways, subroutines. Cell Death Differ 17(5): 763-73.

31. Liang Q, Li W, Zhou B (2008). Caspase-independent apoptosis in yeast. Biochimica et biophysica acta 1783(7): 1311-9.

32. Madeo F, Carmona-Gutierrez D, Ring J, Buttner S, Eisenberg T, Kroemer G (2009). Caspase-dependent and caspase-independent cell death pathways in yeast. Biochem Biophys Res Commun 382(2): 227 31.

33. Munoz AJ, Wanichthanarak K, Meza E, Petranovic D (2012). Systems biology of yeast cell death. FEMS yeast research 12(2): 24965.

34. Wong AH, Yan C, Shi Y (2012). Crystal structure of the yeast metacaspase Yca1. The Journal of biological chemistry 287(35): 29251-9.
35. Wilkinson D, Ramsdale $M$ (2011). Proteases and caspase-like activity in the yeast Saccharomyces cerevisiae. Biochemical Society transactions 39(5): 1502-8.

36. Leger T, Garcia C, Ounissi M, Lelandais G, Camadro JM (2015). The metacaspase (Mca1p) has a dual role in farnesol-induced apoptosis in Candida albicans. Molecular \& cellular proteomics : MCP 14(1): 93108.

37. Strich R (2015). Programmed Cell Death Initiation and Execution in Budding Yeast. Genetics 200(4): 1003-14.

38. Shirtliff ME, Krom BP, Meijering RA, Peters BM, Zhu J, Scheper MA, Harris ML, Jabra-Rizk MA (2009). Farnesol-induced apoptosis in Candida albicans. Antimicrobial agents and chemotherapy 53(6): 2392-401.

39. Fonzi WA, Irwin MY (1993). Isogenic strain construction and gene mapping in Candida albicans. Genetics 134(3): 717-28.

40. Aerts AM, Carmona-Gutierrez D, Lefevre S, Govaert G, Francois IE, Madeo F, Santos R, Cammue BP, Thevissen K (2009). The antifungal plant defensin RsAFP2 from radish induces apoptosis in a metacaspase independent way in Candida albicans. FEBS letters 583(15): 2513-6.

41. Nguyen KT, Ta $\mathrm{P}$, Hoang BT, Cheng $\mathrm{S}$, Hao B, Nguyen $\mathrm{MH}$, Clancy CJ (2009). Anidulafungin is fungicidal and exerts a variety of postantifungal effects against Candida albicans, C. glabrata, C. parapsilosis, and $C$. krusei isolates. Antimicrobial agents and chemotherapy 53(8): 3347-52.

42. Bauer J, Wendland J (2007). Candida albicans Sfl1 suppresses flocculation and filamentation. Eukaryotic cell 6(10): 1736-44.

43. Hornby JM, Jensen EC, Lisec AD, Tasto JJ, Jahnke B, Shoemaker R, Dussault $P$, Nickerson KW (2001). Quorum sensing in the dimorphic fungus Candida albicans is mediated by farnesol. Applied and environmental microbiology 67(7): 2982-92.

44. Mazzoni C, Falcone C (2008). Caspase-dependent apoptosis in yeast. Biochimica et biophysica acta 1783(7): 1320-7.

45. Cao Y, Huang S, Dai B, Zhu Z, Lu H, Dong L, Cao Y, Wang Y, Gao P, Chai $Y$, Jiang $Y$ (2009). Candida albicans cells lacking CaMCA1-encoded metacaspase show resistance to oxidative stress-induced death and change in energy metabolism. Fungal genetics and biology : FG \& B 46(2): 183-9.

46. Erhardt M, Wegrzyn RD, Deuerling E (2010). Extra N-terminal residues have a profound effect on the aggregation properties of the potential yeast prion protein Mca1. PloS one 5(3): e9929.

47. Lee RE, Brunette S, Puente LG, Megeney LA (2010). Metacaspase Yca1 is required for clearance of insoluble protein aggregates. Proceedings of the National Academy of Sciences of the United States of America 107(30): 13348-53.

48. Shrestha A, Puente LG, Brunette S, Megeney LA (2013). The role of Yca1 in proteostasis. Yca1 regulates the composition of the insoluble proteome. Journal of proteomics 81:24-30.

49. Hill SM, Hao X, Liu B, Nystrom T (2014). Life-span extension by a metacaspase in the yeast Saccharomyces cerevisiae. Science 344(6190): 1389-92.

50. Watamoto $T$, Samaranayake LP, Jayatilake JA, Egusa $H$, Yatani $H$, Seneviratne CJ (2009). Effect of filamentation and mode of growth on antifungal susceptibility of Candida albicans. International journal of antimicrobial agents 34(4): 333-9.

51. Burke DJ, Amberg DC, Strathern JN (2005). Methods in Yeast Genetics: A Cold Spring Harbor Laboratory Course Manual. Cold Spring Harbor Laboratory Press, Cold Spring Harbor, NY. 
52. Lee KL, Buckley HR, Campbell CC (1975). An amino acid liquid synthetic medium for the development of mycelial and yeast forms of Candida Albicans. Sabouraudia 13(2): 148-53. 